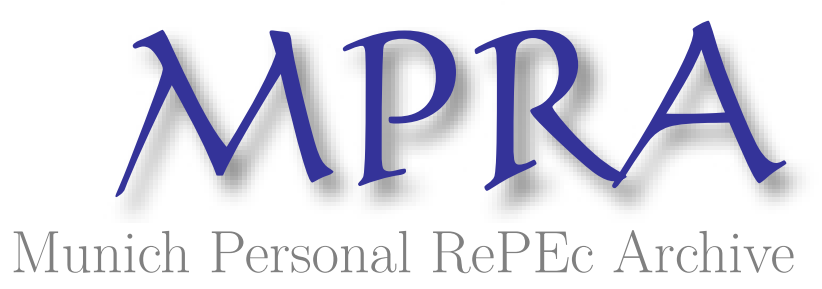

\title{
Explaining persistent cycles in a short-run context: firms' propensity to invest and omnipotent shareholders
}

Charles, Sébastien

University of Paris 8

2009

Online at https://mpra.ub.uni-muenchen.de/18520/

MPRA Paper No. 18520, posted 11 Nov 2009 00:00 UTC 


\title{
Explaining Persistent Cycles in a Short-Run Context: Firms' Propensity to Invest and Omnipotent Shareholders
}

\author{
Sébastien CHARLES \\ Department of Economics, LED \\ University of Paris 8
}

\begin{abstract}
:
In this article, we develop a standard short-run Kaleckian macromodel. First, we study the stability of equilibrium and make some comparative static exercises. Then, we take into account different specifications for an endogenous propensity to invest and systematically analyze the short-run dynamics of the model. We show that when firms' managers adopt abnormal behaviours due to pressures from shareholders regarding the propensity to invest the system exhibits persistent cycles and chaotic trajectories. The analysis emphasizes that, even in the short-run, shareholders may generate instability which represents a serious threat that should not be underestimated for a capitalist economy.
\end{abstract}

Key words: Kaleckian model, propensity to invest, fluctuations JEL classification: B59, E12, E32 


\section{Introduction*}

A large range of studies concerning the theory of endogenous business cycles exists in the economic literature. Macroeconomic models relating the cyclical dynamics of capital stock and global income have been developed initially by Kaldor (1940), probably one of the first economists to realize the importance of non-linearity. This model has been extended and updated by, among others, Chang and Smyth (1971), Semmler (1987) and Grasman and Wentzel (1994). In the same optic, persistent fluctuations have also been discovered in the more standard scope of the IS-LM model as in Schinasi (1982) and Day and Shafer (1985). In these theoretical frameworks, ad hoc nonlinearities contained in the investment and saving equations are the main cause explaining the appearance of cycles or chaos.

This article adopts a slight different approach than the previous analyses. In our approach, nonlinearities appear more naturally through the existence of an endogenous firms' propensity to invest. To the best of our knowledge, little attention has been paid to this variable despite its fundamental role on the economic activity. For instance, a variable propensity to invest may allow us to assess the capability of stockholders to influence the investment decisionmaking process. The aim of this paper is to show that abnormal behaviours from firms, leading, by extension, to abnormal values of the propensity to invest, are able to modify the stability of a simple neo-Kaleckian macromodel, extending to short-run dynamics the conclusions yet obtained in the long-run by Post-Keynesians researches (on this point see, for example, Charles, 2008a).

In this paper, a systematic analysis of this propensity to invest is done by proposing three different theoretical models. Consequently, the outline of the paper is as follows. First, we present the main assumptions and the structure of a nearly standard neo-Kaleckian model in discrete time with a constant propensity to invest. We also study the short-run stability

\footnotetext{
* The author is associate professor in the department of Economics, LED (Laboratoire d'économie dionysien), University of Paris 8.
} 
conditions by making use of a simple phase diagram. Second, we extend this approach by endogenizing the propensity to invest. Here, we deal with two different views; the first refers to normal behaviours from firms whereas the second is intended to represent abnormal behaviours, often due to shareholder pressures on managers. This allows us to show a large variety of dynamics. It turns out that abnormal behaviours may lead to the appearance of persistent cycles and chaotic trajectories even in the short-run. In the final section, we draw some conclusions.

\section{A neo-Kaleckian model with a constant propensity to invest}

We start by assuming a closed economy without government economic intervention that may be represented through a short-run macromodel. Global demand is not enough to ensure full capacity utilization of capital and labour. In this article we shall not deal with price flexibility, leaving this concept for future research or to existing contributions (see Lima and Meirelles, 2003; Asada, 2004). The division of national income is:

$$
p Y=w L+\Pi
$$

where $Y$ the national income, $w$ the nominal wage rate, $L$ the employed quantity of labour and $\Pi$ the level of gross profits. Firms, operating in an imperfect goods market, set price according to a standard mark-up rule on exogenous unit-labour costs:

$$
p=(1+m) w l
$$

with $m>0$ and $l>0$ respectively standing for the mark-up and the constant labour-output ratio. We immediately see that the amount of profits is $\Pi=m w L$. Some simple manipulations of equations (1) and (2) give the profit share in nominal income $0<\pi<1$ :

$$
\pi=\frac{\Pi}{p Y}=1-\left(\frac{w}{p}\right) l=\frac{m}{1+m}
$$


Hereafter, to keep things simple, we shall assume that $p=1$. The profit rate $r$ is the proportion of profits in nominal capital stock. Following the usual disaggregating method contained in heterodox analyses (Taylor, 1983; Lavoie, 1992; Lima and Meirelles, 2006) the macroeconomic profit rate is:

$$
r=\frac{\Pi}{K}=\frac{Y}{K} \frac{\Pi}{Y}=u \pi
$$

where $u$ the output-capital ratio is a proxy for the rate of capacity use.

Turning our attention to saving behaviours, we have the quasi-complete saving function, including differentiated propensities to save, previously utilized in several Post-Keynesian macromodels (see, among others, Charles 2008b):

$$
g^{s}=S / K=s_{f}(r-i d)+s_{c}\left[\left(1-s_{f}\right)(r-i d)+i d\right]
$$

We postulate the existence of three agents: firms, capitalists and workers. Firms save a portion, $0<s_{f}<1$, of their net profits, $r-i d$, and capitalists a portion, $0<s_{c}<1$, of their revenues including distributed dividends, $\left(1-s_{f}\right)(r-i d)$, and interest receipts from firms, $i d$. Moreover, for the sake of simplicity, we assume that workers as a class do not save, so their expenditure is exactly equal to their wage income, $C=W$, explaining why they do not appear in expression (5).

As for the investment function we adopt the following simple form:

$$
g^{d}=I / K=\alpha+\beta s_{f}(r-i d)
$$

Equation (6) is mainly based on the level of net retained earnings and on a positive parameter, $\alpha$, representing animal spirits. Here, $\beta$ represents the sensitivity of accumulation to net retained profits (also called propensity to invest). We already know that internal available funds represent a variable of great importance in heterodox Keynesian models as shown by the empirical works of Fazzari, Hubbard and Petersen (1988) and Ndikumana (1999). This section dealing with a constant propensity to invest, we have $\beta>0$ that represents our normal 
case and, by extension, normal behaviours from firms. However, in the following sections, we shall try to analyse what happens with an endogenous propensity to invest, admitting that managers adopt abnormal behaviours under the pressure of stockholders. In this article, expression (6) focuses exclusively on internal resources, leaving the analysis of capacity utilization or the direct effect of interest rate to more sophisticated developments (see Lavoie and Godley, 2001-2002). For instance, the introduction of a capacity effect in the investment function would have not change the results obtained in terms of dynamics, only adding a major degree of complexity to our presentation. Finally, remaining in the short-run, the level of indebtedness is assumed to be constant.

Replacing $r$ by its value from expression (4) into $g^{d}$ and $g^{s}$ and assuming a growth rate equilibrium on the goods market, we find the following equilibrium value for the rate of capacity utilization with an exogenous propensity to invest:

$$
\tilde{u}=\frac{\alpha-s_{f}\left(\beta+s_{c}-1\right) i d}{\pi\left[s_{f}(1-\beta)+s_{c}\left(1-s_{f}\right)\right]}
$$

Then, introducing (7) into (4) gives the macroeconomic rate of profit:

$$
\tilde{r}=\frac{\alpha-s_{f}\left(\beta+s_{c}-1\right) i d}{s_{f}(1-\beta)+s_{c}\left(1-s_{f}\right)}
$$

and (8) into (6) the rate of accumulation:

$$
\tilde{g}=\frac{\alpha\left[s_{f}+s_{c}\left(1-s_{f}\right)\right]-\beta s_{f} s_{c} i d}{s_{f}(1-\beta)+s_{c}\left(1-s_{f}\right)}
$$

A quick inspection of these expressions indicates that the denominator is always positive whatever the different propensities of the model. Furthermore, the numerator of (7) and (8) must be positive to be economically significant, which is not the case for the level of investment that can be negative, at least in the scope of short-run dynamics. In line with the Post-Keynesian theory of income distribution, we know that capitalists have a high propensity to save, $s_{c}$, so we may be sure that $\left(s_{c}+\beta-1\right)>0$. 
Concerning short-run stability and recalling that this economy is operating with excess capacity, we assume the standard Keynesian adjustment mechanism according to which output, through the rate of capacity utilization, changes with excess demand on the goods market. So, we have the following difference equation:

$$
\Delta u_{t+1} \equiv u_{t+1}-u_{t}=\varphi\left(g_{t}^{d}-g_{t}^{s}\right)
$$

Hereafter, for simplicity, we assume that, $\varphi$, the speed of adjustment between investment and saving is equal to unity. Introducing (8) into (5) and (6) and the corresponding expressions into equation (9) we find:

$$
u_{t+1}=\left[\alpha-s_{f}\left(\beta+s_{c}-1\right) i d\right]+\left\{1-\pi\left[s_{f}(1-\beta)+s_{c}\left(1-s_{f}\right)\right]\right\} u_{t}
$$

Mathematically, the stability condition for a linear first order difference equation implies that $\left|\partial u_{t+1} / \partial u_{t}\right|<1$ (see Shone, 2002), which gives:

$$
1-\pi\left[s_{f}(1-\beta)+s_{c}\left(1-s_{f}\right)\right]<1 \Leftrightarrow s_{f}(1-\beta)+s_{c}\left(1-s_{f}\right)>0
$$

Economically, convergence is ensured in Kaleckian models if investment is less sensitive to variation in capacity use than saving $\left(\partial g_{t}^{d} / \partial u_{t}<\partial g_{t}^{s} / \partial u_{t}\right)$. This condition holds in our model since the denominator of (7) and (8) is always positive, as established above. Recalling that $\alpha-s_{f}\left(\beta+s_{c}-1\right) i d>0$, a simple phase diagram also shows that $\tilde{u}$ is an attracting stable fixed point (see Figure 1).

\section{Here Figure 1}

A further step consists of making some comparative static exercises, indicating the effect of a variation in animal spirits, the interest rate, the level of indebtedness or the capitalists' propensity to save. Consider a rise in the level of animal spirits as represented by the 
parameter $\alpha$. This can be associated with more optimistic expectations about future economic conditions. Then, the rate of capacity use and profits increase due to a rise in investment.

Other experiments show that increasing indebtedness or the rate of interest has a negative effect on $\tilde{u}$. We know that a higher interest rate (or debt) reduces the level of investment through the cash flow effect contained in equation (6). Nevertheless, a higher $i$ also increases capitalists' consumption by providing them a surplus of income. Here, the former effect is greater than the latter since capitalists' propensity to spend, $c_{c}=1-s_{c}$, is relatively small, implying that an increase in $i$ or $d$ has a negative impact on capacity utilization and profits.

The next step consists in assessing the variation in the capitalists' propensity to save out of income. Some simple calculations unambiguously show that an increase in $s_{c}$ has a negative effect on economic activity (see Figure 2). This conclusion is in line with standard neoKaleckian model of growth and distribution.

\section{Here Figure 2}

Another interesting result is that a fall in the propensity to invest diminishes the rate of utilization, through its negative effect on investment as shown by equation (6). To us, such a change means that firms adopt a less cautious behaviour by neglecting safe internal finance.

The last exercise indicates that our model is stagnationist in essence. This means that a rise in the real wage, implying a fall in the share of profit, causes an increase in the rate of capacity use. The explanation is the following: a rise in the real wage redistributes income from firms and capitalists, with a small propensity to spend, towards workers with a propensity to spend equals to unity. This generates a positive economic effect due to the rise in consumption demand, emanating from workers. Note that a different specification of the 
investment function may change the stagnationist behaviour of an economy as shown in Badhuri and Marglin (1990) and Blecker (2002). Our main results are summarised in Table 1.

\section{Here Table 1}

In the following section, the main novelty regards the introduction of a variable propensity to invest in the previous short-run macromodel. Then, we shall deal with two different theoretical constructions. The first refers to normal behaviours from firms, the second incorporates abnormal behaviours due to stockholders pressures.

\section{Short-run dynamics in the normal case}

To the best of our knowledge, no authors deal with an endogenous propensity to invest, except Delli Gatti, Gallegati and Gardini (1993) and Delli Gatti, Gallegati (1994), though not in a Kaleckian framework. Hereafter, we explicitly follow their studies by assuming that the propensity to invest is procyclical. To avoid useless complexity we assume the linear relation:

$$
\beta=\beta\left(u_{t}\right)=\beta_{0} u_{t} \quad \beta_{0}>0
$$

This positive causality is based on the well known study of Fazzari, Hubbard and Petersen (1988). According to them, the global propensity to invest, $\beta_{0}$, is a weighted average of the high propensity to invest of small firms (with high rate of growth of sales) and of the small propensity to invest of big firms. Therefore, during an economic expansion small firms grow more quickly than big firms which leads to an increase in their weight and in the global propensity to invest. Introducing the new expression for $\beta$ into (10) we have: 


$$
\begin{aligned}
& u_{t+1}=\varepsilon_{0}+\left(1-\varepsilon_{1}\right) u_{t}+\varepsilon_{2} u_{t}^{2} \\
& \left\{\begin{array}{l}
\varepsilon_{0}=\alpha+s_{f}\left(1-s_{c}\right) i d \\
\varepsilon_{1}=\beta_{0} s_{f} i d+\pi\left[s_{f}+s_{c}\left(1-s_{f}\right)\right] \\
\varepsilon_{2}=\pi \beta_{0} s_{f}
\end{array}\right.
\end{aligned}
$$

where $\varepsilon_{i=0,1,2}>0$. Computations indicate that equation (13) is a hyperbolic curve in the $u_{t+1} / u_{t}$ plan with an inflexion point $\bar{u}=\left(\varepsilon_{1}-1\right) / 2 \varepsilon_{2}<0$ (see Figure 3$)$ :

$$
\partial u_{t+1} / \partial u_{t}>_{0} \Rightarrow u_{t}<_{\bar{u}}
$$

\section{Here Figure 3}

Potentially, two equilibria exist, however we shall not deal with the unstable one since it is located, for plausible values of parameters, beyond the maximum logical value $u=1$. Indeed, assuming a positive shock $u_{0}>1$ would have no economic meaning. Assessing dynamic trajectories, after a variation of parameters, is now more difficult due to the presence of nonlinearities. To overcome this difficulty we perform simple numerical simulations, adopting a standard presentation that shows systematically the phase diagram and the corresponding dynamics through time. For the set of initial parameters given in Table 2 and assuming a strong negative shock, $u_{0}=0.2$, Figure 4 establishes capacity use at $\tilde{u}=0.67$.

Here Table 2

Here Figure 4

\section{Here Figure 5}


Other experiments in Figure 5 show that a fall in the capitalists' propensity to save $\left(s_{c}=0.6\right)$ tends to increase the rate of capacity utilization, since it generates a rise in demand emanating from capitalists. Furthermore, simulations (see Figure 6) indicate that a permanent decrease in the parameter $\beta_{0}$ also diminishes output. With $\beta_{0}=0.5$ the rate of utilization, $\tilde{u}$, goes down from 0.67 to 0.61 , keeping intact the whole conclusions made in section two for the model with an exogenous sensitivity to cash flows. In what follows, we shall examine whether abnormal behaviours from firms, by changing the propensity to invest, are able to modify the stability of this short-run Kaleckian macromodel.

\section{Here Figure 6}

\section{Short-run dynamics in the abnormal case: the omnipotence of shareholders}

In this section we put forward an alternative explanation of the propensity to invest contained in well-known Post-Keynesian models such as Delli Gatti, Gallegati and Gardini (1993). Note that our aim is not to question these contributions but rather to extend them by introducing the destabilizing impact of shareholders with short-term plans, leading to abnormal values of the propensity to invest and to abnormal economic situations. Then, we assume the following causal mechanism for $\beta$ :

$$
\beta=\beta_{1}-\beta_{2} u_{t}
$$

with $\beta_{i=1,2}>0$. First, expression (15) seems rather strange since it indicates that a rise in the rate of capacity utilization causes a fall in the propensity to invest. This apparent paradox is easily explained by incorporating, as we said above, the presence of stockholders represented by institutions like banks or pension funds. The rationale is that shareholders may refuse the investment policy needed to respond to a rise in output because it threatens the profitability of their assets in the short-run. For example, the decision to invest may perfectly involve an 
immediate and prolonged rise in the retention rate, to ensure safe growth through larger internal funds. This is unacceptable for shareholders with short-term views since it would mechanically diminish the amount of their dividends. In a financial capitalist economy, the primacy of stockholders is such that they have the capability to ask for abnormal requests; postponing accumulation projects is obviously one of them. We think that such a situation, though corresponding to a particular case, cannot be eliminated from the analysis. Therefore, the existence of omnipotent shareholders explains why an increase in the rate of capacity utilization may lead to a fall in the propensity to invest. This is what we shall designate as our abnormal case. Note that our proposition may also be seen as a first attempt to formalize one of the possible cases of discord between stockholders and managers as extensively developed by the study of Crotty (1990).

Turning our attention to formalization, the only logical constraint is to keep $\tilde{u} \leq 1$. For $\beta=0$ the rate of capacity reaches is maximum value, assuming $\beta_{1} \leq \beta_{2}$ ensures that we respect the above condition. A sudden change in shareholder behaviours may be captured through a variation in the parameter $\beta_{2}$. Thus, it is shown that an increment in $\beta_{2}$ moves the curve down, indicating that, for an unchanged level of capacity, managers yield to shareholder demands. In that case, they accept to decrease their propensity to invest and to completely revise their investment plans. For abnormal demands from shareholders a very risky situation appears as shown by the curve $\beta^{\prime \prime \prime}$ (see Figure 7). Indeed, a negative propensity to invest corresponds to a very abnormal situation in which firms utilize their retained earnings to buy financial assets instead of investing.

\section{Here Figure 7}


Having presented the behaviour of shareholders with regard to profits, we may now turn back to our short-run dynamics in order to assess their impact on this Kaleckian economy. Now, introducing equation (15) into (10) we find a non linear first order difference equation of the form:

$$
\begin{aligned}
& u_{t+1}=\varepsilon_{0}+\left(1+\varepsilon_{1}\right) u_{t}-\varepsilon_{2} u_{t}^{2} \\
& \left\{\begin{array}{l}
\varepsilon_{0}=\alpha-s_{f}\left(\beta_{1}+s_{c}-1\right) i d \\
\varepsilon_{1}=\beta_{2} s_{f} i d-\pi\left[s_{f}\left(1-\beta_{1}\right)+s_{c}\left(1-s_{f}\right)\right] \\
\varepsilon_{2}=\pi \beta_{2} s_{f}
\end{array}\right.
\end{aligned}
$$

and $\varepsilon_{i=0,2}>0, \varepsilon_{1}^{>}<0$. Some simple calculations show that equation (16) is a parabolic curve in the plan with a positive inflexion point $\bar{u}=\left(1+\varepsilon_{1}\right) / 2 \varepsilon_{2}$ (see Figure 8$)$ :

$$
\partial u_{t+1} / \partial u_{t}>0 \Rightarrow u_{t}<\bar{u}
$$

Equation (16) has two solutions:

$$
\tilde{u}^{\prime}, \tilde{u}^{\prime \prime}=\frac{-\varepsilon_{1} \pm \sqrt{\varepsilon_{1}^{2}+4 \varepsilon_{2} \varepsilon_{0}}}{2 \varepsilon_{2}} \quad \text { with } \tilde{u}^{\prime}>0, \tilde{u}^{\prime \prime}<0
$$

\section{Here Figure 8}

For a non linear difference equation, the stability of equilibrium requires (see the appendix) the inequality $\left|\partial u_{t+1} / \partial u_{t+1}(\tilde{u})\right|<1$. Ignoring $\widetilde{u}^{\prime \prime}<0$, this gives: $-1<\left|2 \varepsilon_{1}+\sqrt{\varepsilon_{1}^{2}+4 \varepsilon_{0} \varepsilon_{2}}+1\right|<1$. Since there still exists an indeterminacy concerning the previous inequality, we need to perform some numerical simulations to find the short-run dynamics of this neo-Kaleckian macromodel. In what follows, we shall focus on an increasing impact - in the sense of more pressures - of shareholders on managers, through a rise in the parameter $\beta_{2}$. Then, we assign the following values for the model's parameters. 


\section{Here Table 3}

In addition, we choose the initial condition $u_{0}=0.2$. Figure 9 shows that equilibrium is stable around $\tilde{u}=0.86$ and exogenous shocks do not affect the short-run economic equilibrium. A sufficiently low level of $\beta_{2}$ indicates that shareholder demands remain in reasonable limits, keeping the aggregate propensity to invest, $\beta$, positive and high enough to have a significant level of investment spending.

\section{Here Figure 9}

Assuming an increase in the parameter $\beta_{2}$ to 10.0 , meaning that firms' managers yield to shareholder requests, by diminishing their accumulation plans, leads to a two-period cycle (see Figure 10). Therefore, our first result underlines that, all else being constant, when stockholders ask for less investment this generates both persistent cycles and a recession, though the propensity to invest remains positive.

\section{Here Figure 10}

As shareholders demand stronger investment cut this generates an abnormal economic situation in which the propensity to invest becomes negative, firms utilizing profits to buy financial assets. This abnormal situation, undermining the real sector, is represented by the appearance of a larger instability (Figure 11).

\section{Here Figure 11}




\section{Here Figure 12}

Nevertheless, it is only when $\beta_{2}$ goes beyond a crucial value that the rate of capacity utilization follows a true chaotic motion.(1) For instance, with $\beta_{2}=17.0$, Figure 12 clearly emphasizes that the series is aperiodic. The second result obtained here is that omnipotent shareholders may also be at the origin of chaos, by constraining managers to adopt abnormal behaviours regarding their natural propensity to invest. More generally, by putting pressure on managers, they create a very risky economic situation in the short-term in which firms diminish the level of needed investment to abnormal levels. This kind of configuration is likely to appear simply because stockholders have very short-term planning horizons as recalled by Crotty (1990). Indeed, they are not concerned with the concepts of investment policy, long-term growth and safety of the firm. Consequently, the reason why shareholders may destabilize a capitalist economy, even in the short-run, is because they have the capability to influence investment decisions in the wrong way.

\section{Conclusion}

In this article we first deal with a short-run Kaleckian macromodel in which the propensity to invest is exogenous. We recall the main characteristics regarding the stability of equilibrium and some comparative static results, showing the effect of various parameters (such as interest rates, animal spirits and capitalists' propensity to save out of profits) on the rate of capacity utilization.

Then, we take into account an endogenous propensity to invest and examine to what extent this assumption modifies economic dynamics. We establish that when firms' managers adopt abnormal behaviours, due to pressures from shareholders asking for unreasonable cuts in investment spending, the system loses its stability making room for persistent cycles and 
chaotic trajectories even in the short-run. In consequence, our contribution is an illustration of how stockholders (and institutions that own portfolios) may be destabilizing for a financial capitalist economy.

\section{Appendix}

Consider the non linear difference equation (see Shone, 2002):

$$
x_{t+1}=f\left(x_{t}\right)
$$

An equilibrium point exists if: $x^{*}=f\left(x^{*}\right)$. To show the stability properties of the equilibrium point we take a Taylor expansion of $f$ about $x^{*}$. Ignoring the remainder term a first-order linear approximation gives:

$$
x_{t+1}=f\left(x^{*}\right)+\partial f /\left.\partial x\right|_{x^{*}}\left(x_{t+1}-x^{*}\right)
$$

This procedure reduces the issue of stability to the study of a linear relation. Then, if:

$$
\begin{aligned}
& \left|\partial f / \partial x_{\left(x^{*}\right)}\right|<1 \quad x^{*} \text { is stable } \\
& \left|\partial f / \partial x_{\left(x^{*}\right)}\right|>1 \quad x^{*} \text { is unstable } \\
& \left|\partial f / \partial x_{\left(x^{*}\right)}\right|=1 \text { the stability of } x^{*} \text { is inconclusive }
\end{aligned}
$$




\section{References}

Asada, T. "Price flexibility and Instability in a Macrodynamic Model with Debt Effect." Journal of International Economic Studies, 2004, 18, March, 41-60.

Bhaduri, A., Marglin, S. "Unemployment and the Real Wage: the Economic Basis for Contesting Political Ideologies." Cambridge Journal of Economics, 1990, 14, 4, 375-393.

Benhabib, J. Cycles and Chaos in Economic Equilibrium. Princeton: Princeton University Press, 1992.

Blecker, R. "Distribution, Demand and Growth in Neo-Kaleckian Macro-Models." In Setterfield, M. (ed.), The Economics of Demand-Led Growth. Edward Elgar: Cheltenham, 2002.

Chang, W.W., Smyth, D.J. "The Existence and Persistence of Cycles in a Nonlinear Model: Kaldor's 1940 Model Re-Examined.” Review of Economic Studies, 1971, 38, January, 37-46.

Charles, S. "Corporate Debt, Variable Retention Rate and the Appearance of Financial Fragility." Cambridge Journal of Economics, 2008a, 32, 5, 781-795.

Charles, S. "Teaching Minsky's Financial Instability Hypothesis: a Manageable Suggestion." Journal of Post-Keynesian Economics, 2008b, 31, 1, 127-140.

Crotty, J. R. "Owner-Manager Conflict and Financial Theories of Investment Instability: a Critical Assessment of Keynes, Tobin and Minsky." Journal of Post-Keynesian Economics, 1990, 12, Summer, 519-42.

Day, R.H. Complex Economic Dynamics. Cambridge: MIT Press, 1994.

Day, R.H., Shafer, W. “Keynesian Chaos.” Journal of Macroeconomics, 1985, 7, 3, 277-295.

Delli Gatti D., Gallegati M. "External Finance, Investment expenditure and the Business Cycle." In Semmler, W. (ed.), Business Cycles: Theory and Empirical Methods, Boston: Kluwer Academic Publishers, 1994.

Delli Gatti, D., Gallegati, M, Gardini, L. "Investment, Confidence, Corporate Debt and Income Fluctuations." Journal of Economic Behavior and Organization, 1993, 22, 2, 161187.

Fazzari, S., Hubbard, R. G., Petersen, B. C. "Financing constraints and corporate investment." Brooking Papers on Economic Activity, 1988, 1, 1, 141-95.

Grasman J., Wentzel, J.J. "Co-Existence of a Limit Cycle and an Equilibrium in Kaldor's Business Cycle Model and its Consequences." Journal of Economic Behavior and Organisation, 1994, 24, 3, 369-377.

Kaldor, N. “A Model of the Trade Cycle.” Economic Journal, 1940, 50, March, 78-92. 
Lavoie, M. Foundations of Post-Keynesian Economic Analysis. Edward Elgar: Aldershot, 1992.

Lavoie, M., Godley, W. "Kaleckian Models of Growth in a Coherent Stock-Flow Monetary Framework: A Kaldorian View." Journal of Post-Keynesian Economics, 2001-2002, 24, Winter, 277-312.

Lima, G.T., Meirelles, A.J.A. "Endogenous Banking Mark-up, Distributional Conflict and Capacity Utilization." Metroeconomica, 2003, 54, 2-3, 366-384.

Lima, G.T., Meirelles, A.J.A. "Debt, Financial Fragility and Economic Growth: A Post Keynesian Macromodel.” Journal of Post-Keynesian Economics, 2006, 29, 1, 93-115.

Ndikumana, L. "Debt service, financing constraints and fixed investment: evidence from panel data." Journal of Post-Keynesian Economics, 1999, 21, 3, 455-78.

Schinasi, G.J. "Fluctuations in a Dynamic, Intermediate-Run IS-LM Model." Journal of Economic Theory, 1982, 28, December, 369-375.

Semmler, W. "A Macroeconomic Limit Cycle with Financial Perturbations." Journal of Economic Behavior and Organization, 1987, 8, 3, 469-495.

Shone, R. Economic Dynamics: Phase Diagrams and their Economic Application. Cambridge: Cambridge University Press, 2002.

Taylor, L. Structuralist Macroeconomics, Basic Books: New York, 1983.

\section{Footnotes}

(1) For a complete view of chaos in economics see Benhabib (1992) and Day (1994). 
Figure 1: Stable fixed point for the rate of capacity use

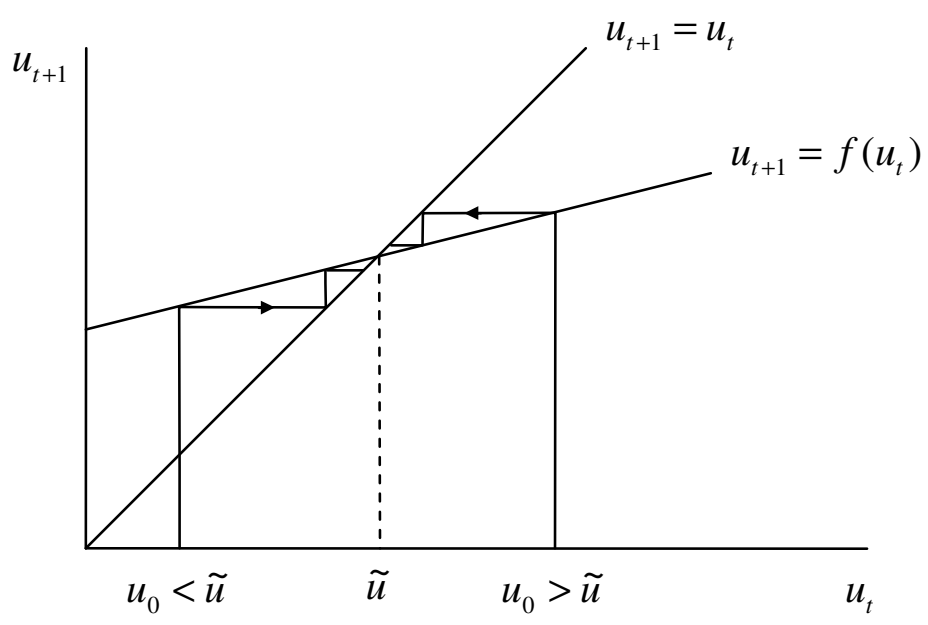

Figure 2: An increase in the capitalists' propensity to save

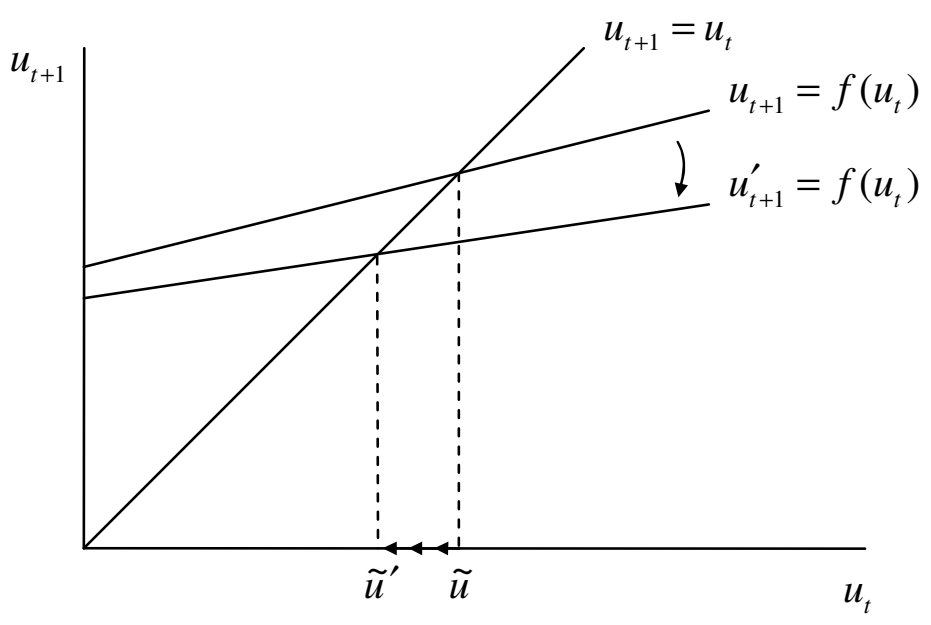

Table 1: Impact of changes in some parameters

\begin{tabular}{ccccccc}
\hline & $\partial \alpha$ & $\partial i$ & $\partial d$ & $\partial \beta$ & $\partial s_{c}$ & $\partial \pi$ \\
\hline$\partial \tilde{u}$ & + & - & - & + & - & - \\
\hline$\partial \tilde{r}$ & + & - & - & + & - & - \\
\hline \hline
\end{tabular}


Figure 3: The utilization curve in the normal case

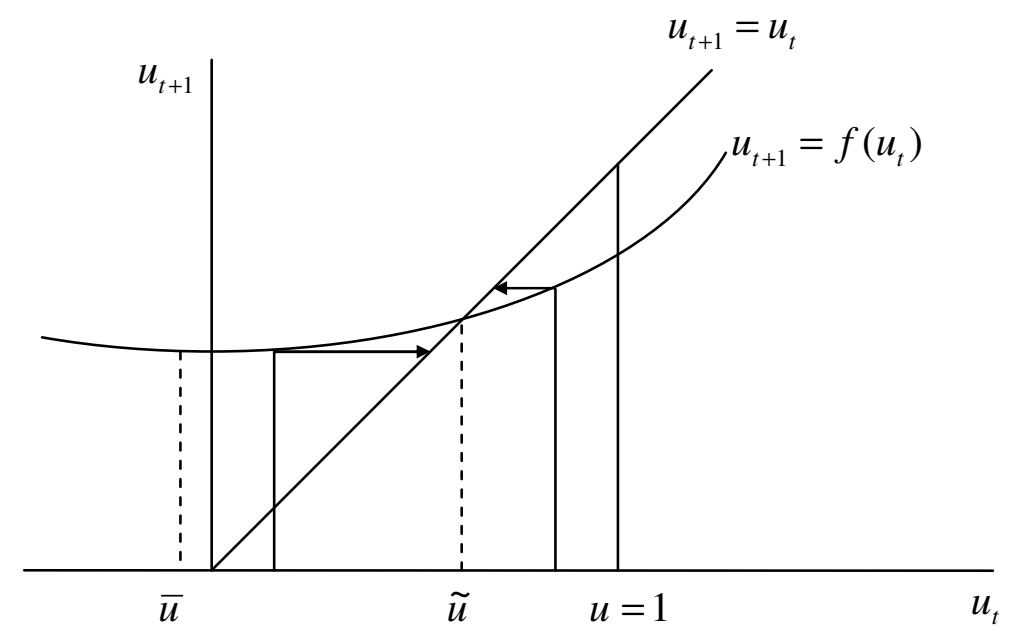

Table 2: Parameters for the normal case

\begin{tabular}{l|c|c|c|c|c|c|c}
\hline \hline Parameters & $\alpha$ & $i$ & $d$ & $\pi$ & $\beta_{0}$ & $s_{f}$ & $s_{c}$ \\
\hline Value & 0.2 & 0.05 & 0.1 & 0.45 & 0.6 & 0.7 & 0.8 \\
\hline \hline
\end{tabular}

Figure 4: Initial equilibrium with $u_{0}=0.2$
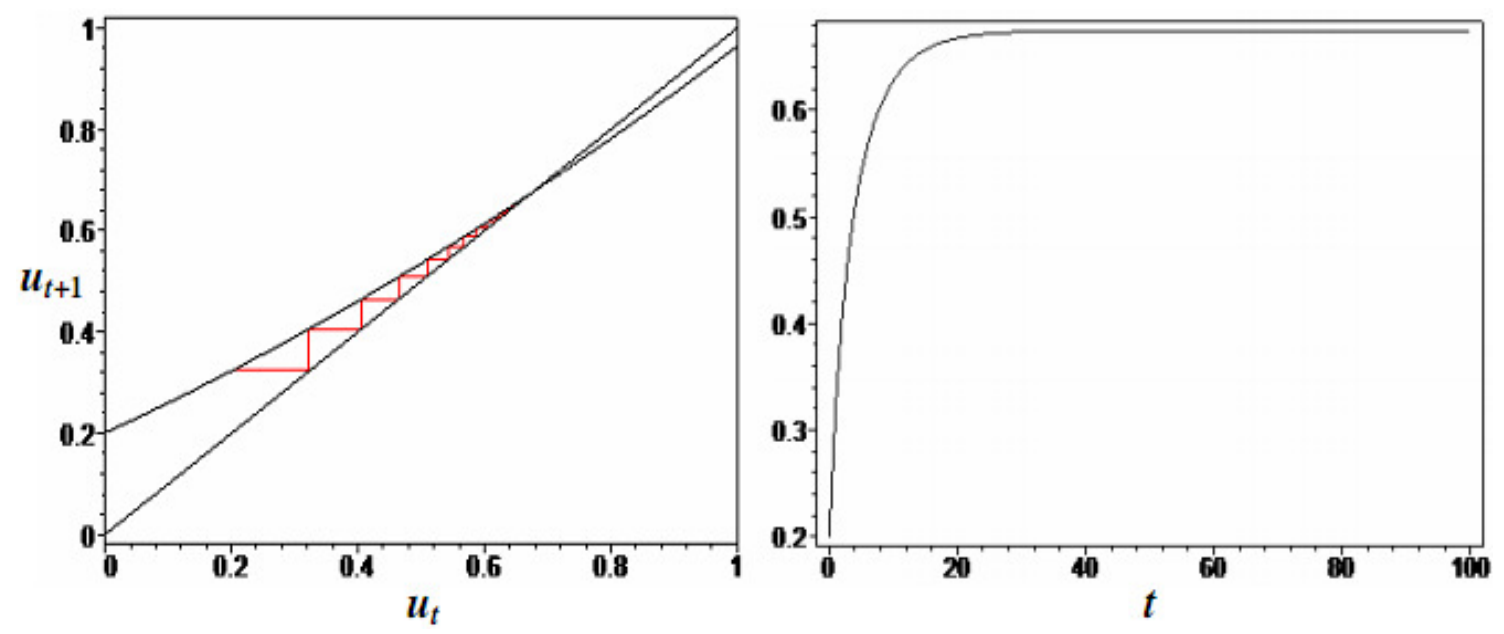
Figure 5: A decrease in the capitalists' propensity to save
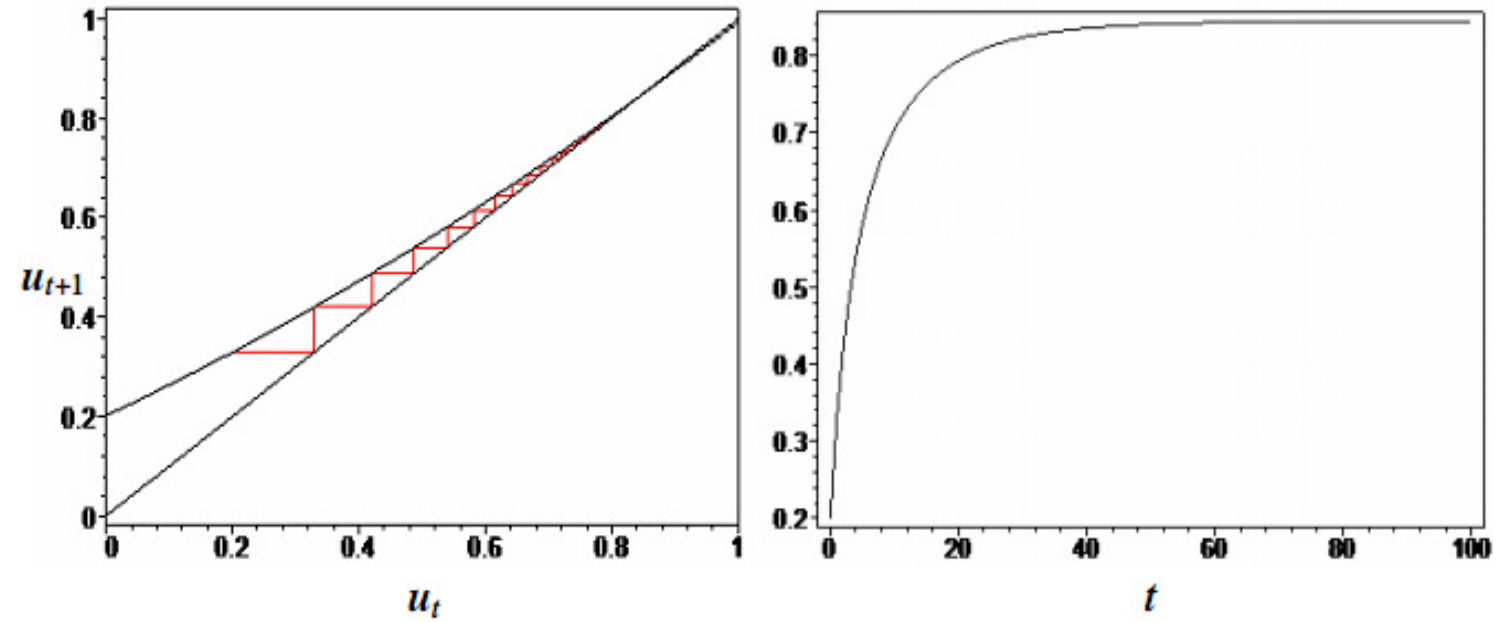

Figure 6: A decrease in the propensity to invest
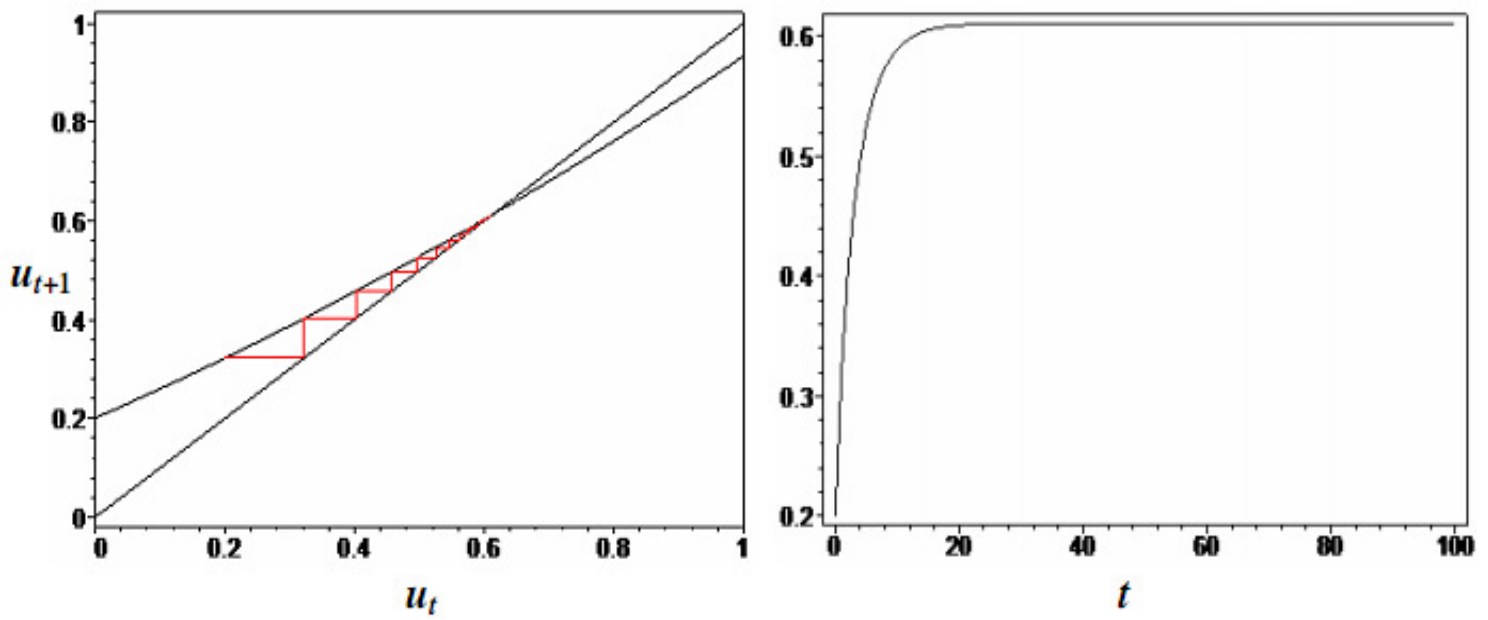

Figure 7: Shareholder behaviours regarding capacity

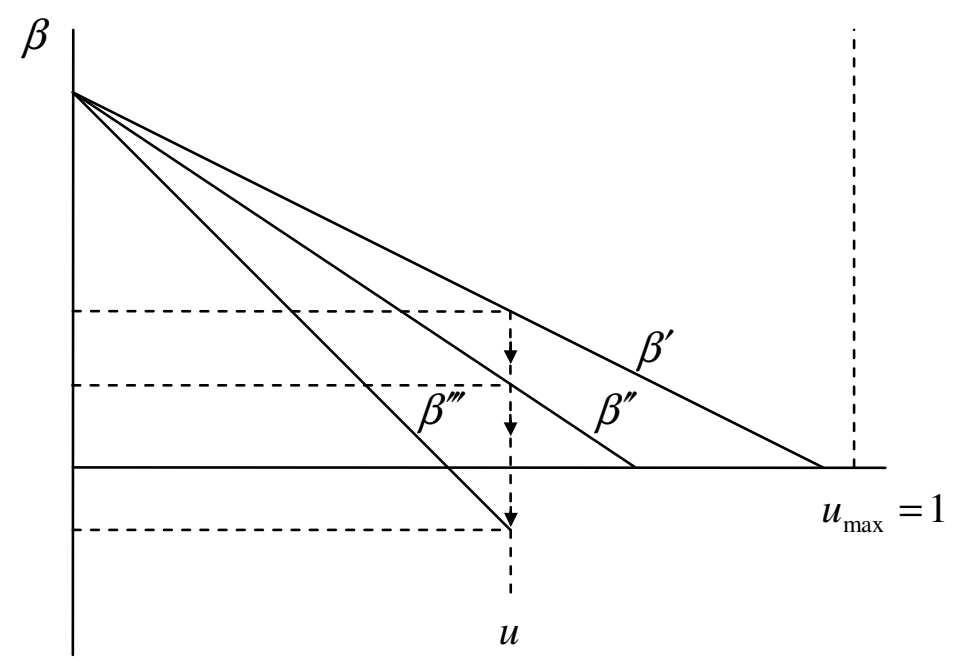


Figure 8: The utilization curve in the abnormal case

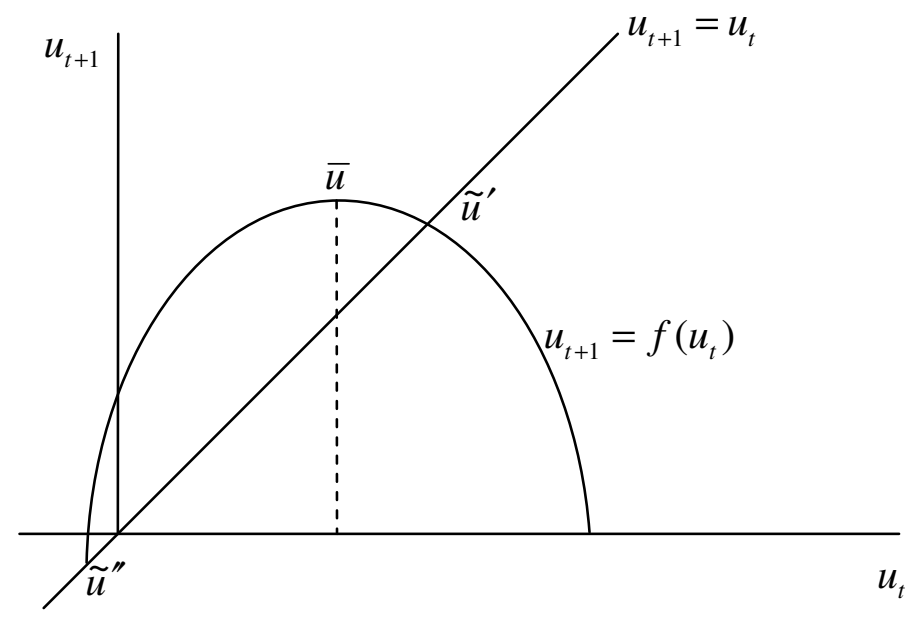

Table 3: Parameters for the abnormal case

\begin{tabular}{l|c|c|c|c|c|c|c|c}
\hline \hline Parameters & $\alpha$ & $i$ & $d$ & $\pi$ & $\beta_{1}$ & $\beta_{2}$ & $s_{f}$ & $s_{c}$ \\
\hline Value & 0.2 & 0.05 & 0.3 & 0.47 & 5.5 & 5.6 & 0.8 & 0.9 \\
\hline \hline
\end{tabular}

Figure 9: Cyclical convergence with $\beta_{2}=5.6$
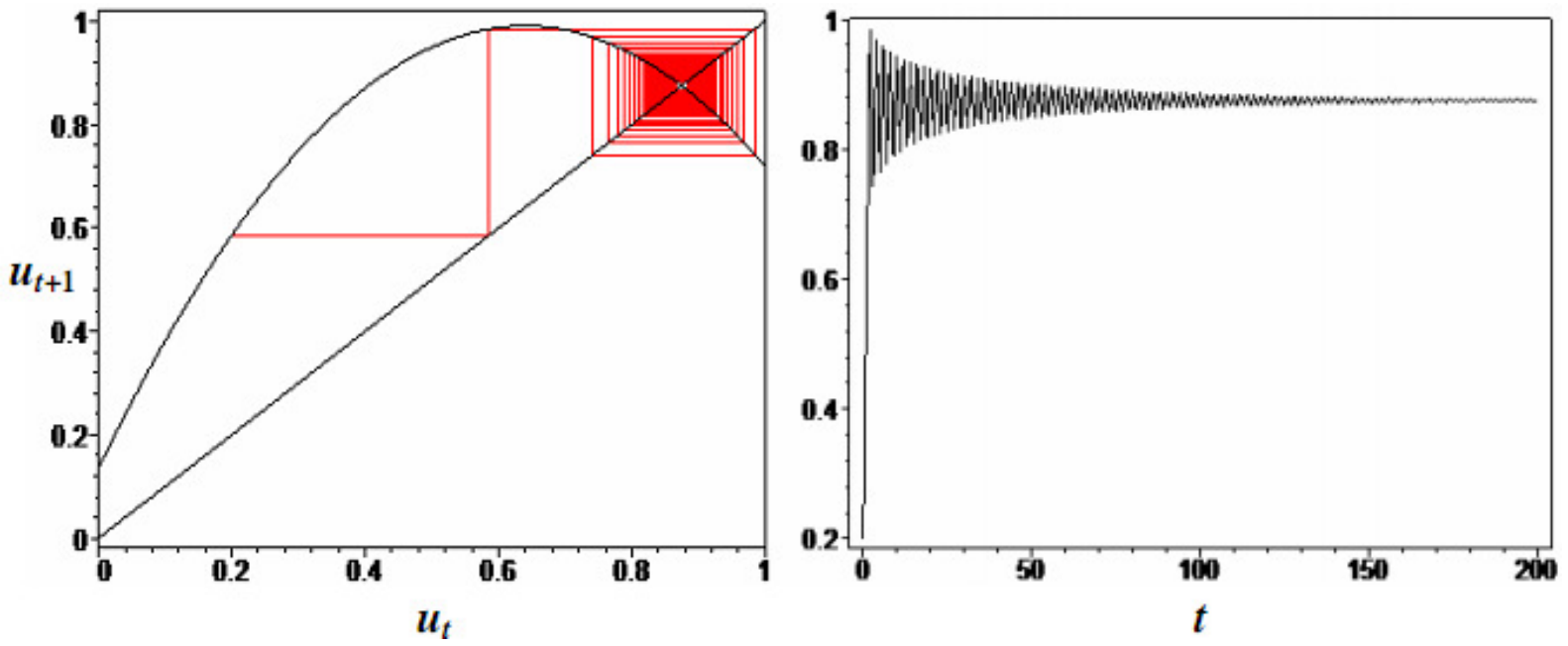
Figure 10: Two-period cycle with $\beta_{2}=10.0$
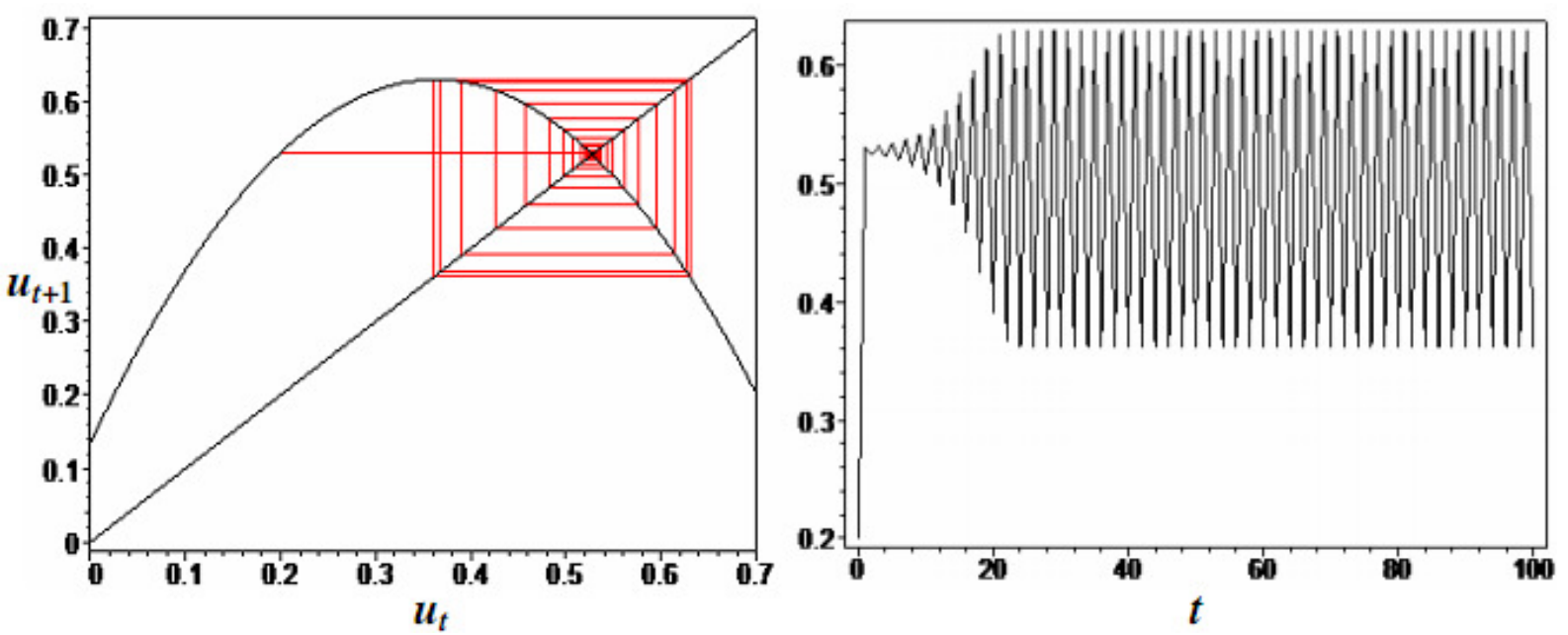

Figure 11: Four-period cycle with $\beta_{2}=14.0$
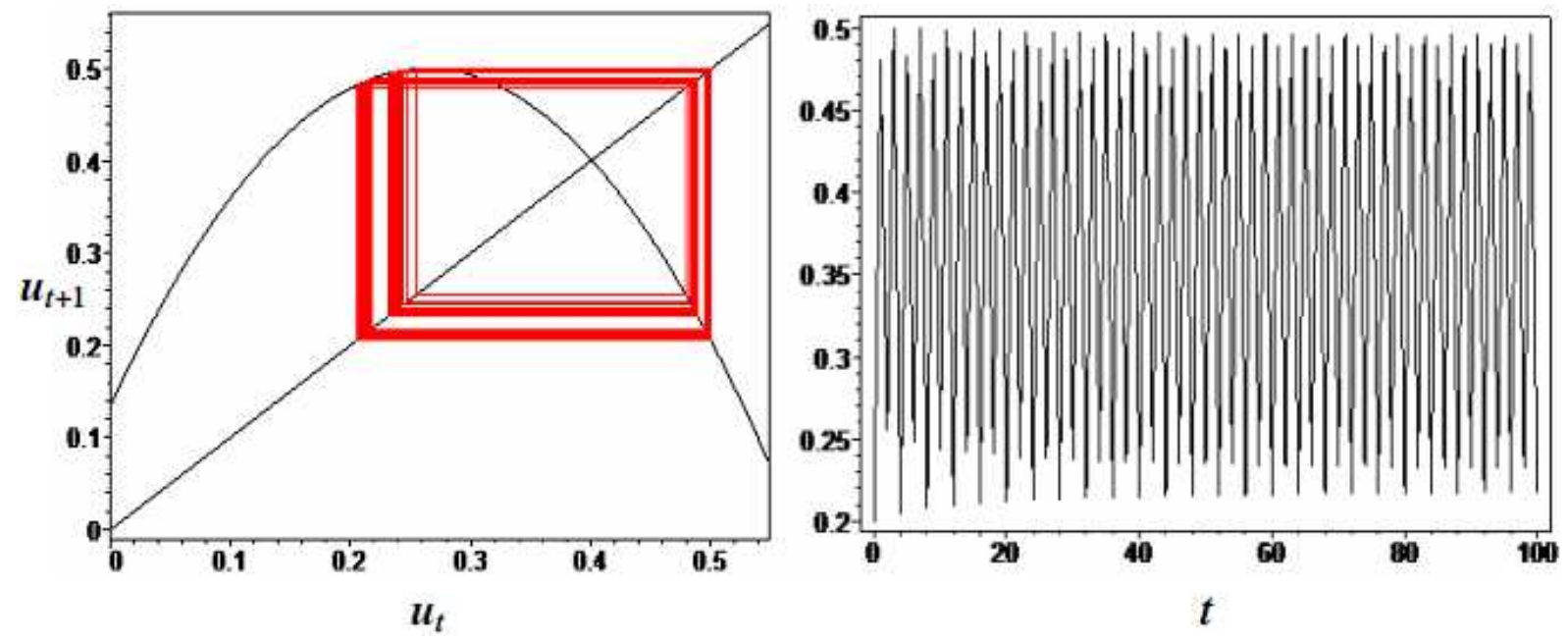

Figure 12: Chaotic dynamics with $\beta_{2}=17.0$
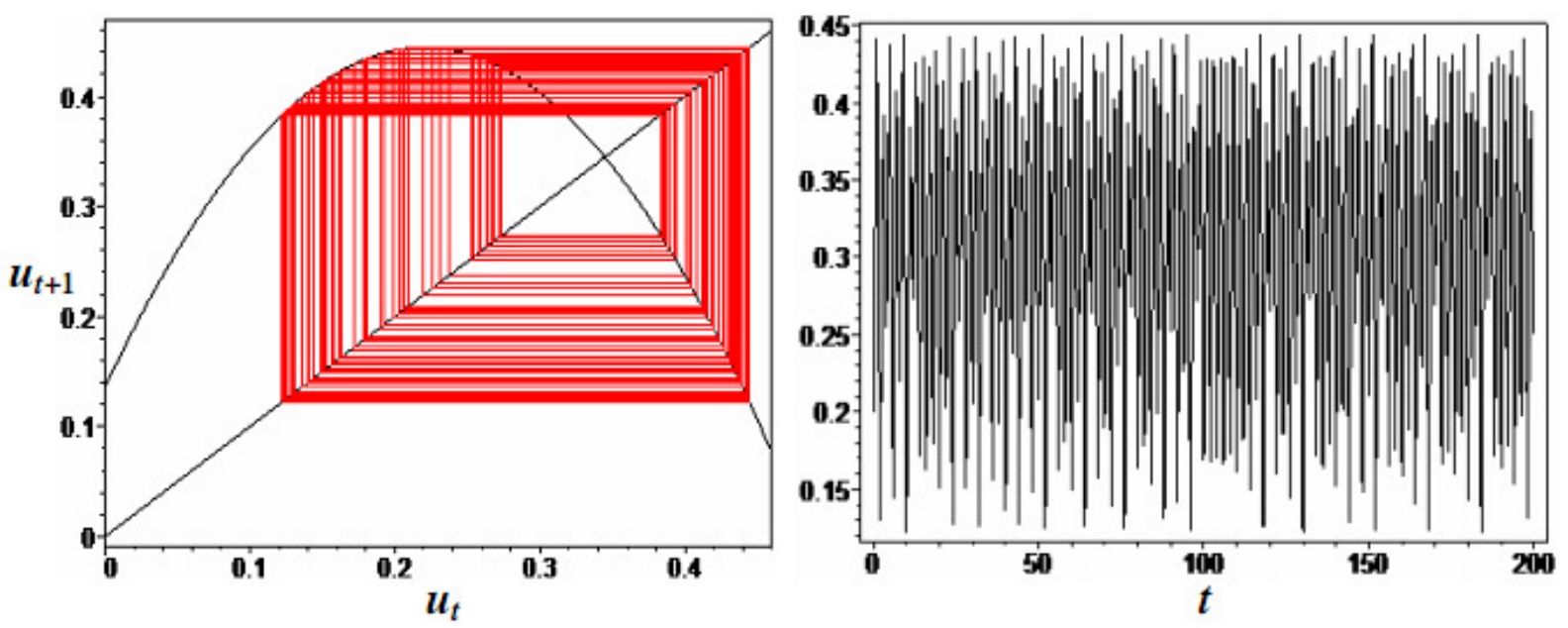